\title{
POTENCIAIS DE REDUÇÃO DE EMISSÕES DE DIÓXIDO DE CARBONO NO SETOR DE TRANSPORTES: UM ESTUDO DE CASO DA LIGAÇÃO HIDROVIÁRIA RIO-NITERÓI
}

\author{
Fatima Cristina Vaz Pinto ${ }^{1}$ \\ Robson Nogueira dos Santos ${ }^{2}$
}

Resumo: O dióxido de carbono $\left(\mathrm{CO}_{2}\right)$ é o principal gás de efeito estufa, sendo a intensificação de suas emissões pelos transportes, uma das principais responsáveis pela ocorrência de mudanças climáticas ao planeta, como o fenômeno do aquecimento global. Este artigo apresenta um estudo de caso em que foram feitas estimativas para a redução de emissões de $\mathrm{CO}_{2}$ a partir da maior utilização de modalidades de transporte que apresentam maior eficiência energética, como é o caso da modalidade hidroviária de passageiros. A partir da análise do sistema hidroviário de passageiros entre os municípios do Rio de Janeiro e de Niterói, foram desenvolvidos dois cenários alternativos contemplando os potenciais de reduções para tais emissões. As principais conclusões obtidas neste estudo mostram que existem grandes potenciais para a redução de $\mathrm{CO}_{2}$ a partir do aumento da demanda de passageiros e da expansão do sistema hidroviário desta ligação.

Palavras-Chave: Sistemas de Transportes, Eficiência Energética, Poluição Atmosférica, Mudanças Climáticas.

\begin{abstract}
Carbon dioxide $\left(\mathrm{CO}_{2}\right)$ it is the main greenhouse effect gas, being the intensification of its emissions for the means of transportation, one of the main responsible factors for the occurrence of climatic changes to the planet, as the phenomenon of the global heating. This article presents a case study in which were made estimates for the reduction of emissions of $\mathrm{CO}_{2}$ starting from the largest use of transport modalities that present greater energy efficiency, as it is the case of the maritime modality of passengers. Starting from the analysis of the maritime system of passengers among the cities of Rio de Janeiro and Niterói, two alternative sceneries were developed contemplating the potentials of reductions for such emissions. The main conclusions obtained in this study show that great potentials exist for the reduction of $\mathrm{CO}_{2}$ starting from the increase of the passengers and the expansion of the maritime system of this connection.
\end{abstract}

Key words: Systems of Transports, Energy Efficiency, Atmospheric Pollution, Climatic Changes.

\footnotetext{
${ }^{1}$ Universidade Federal do Rio de Janeiro - Programa de Pós-Graduação em Engenharia de Transportes - COPPE E-mail: fatimavaz@yahoo.com.br,

${ }^{2}$ Universidade Federal do Rio de Janeiro - Programa de Pós-Graduação em Engenharia de Transportes - COPPE E-mail: rbsns@globo.com
} 


\section{INTRODUÇÃO}

Apesar do papel fundamental que os sistemas de transportes exercem dentro do setor de serviços, esta vem sendo ao longo dos anos uma das atividades humanas que mais impactos produziram ao meio ambiente. Um dos desafios inerentes ao setor de transportes é o de aliar o atendimento à necessidade humana de locomoção com a manutenção do meio ambiente, sem comprometer com isso a qualidade de vida da população.

A geração e o consumo de energia são fatores relacionados com um grande número de alterações ambientais produzidas ao planeta. Pelo fato de utilizar grande parte da energia não-renovável, os transportes contribuem diretamente com impactos relacionados à exploração irracional dos recursos naturais, visto que, comparado aos demais setores econômicos, os transportes utilizam combustíveis de origem fóssil de forma bastante intensa. Tal fato, aliado ao aumento significativo do número de veículos circulando nas grandes cidades, contribui para o agravamento do problema da poluição do ar. A queima de gasolina e óleo diesel pelo setor de transportes é uma das maiores fontes de emissão de gases poluentes em ambientes urbanos.

Os sistemas rodoviários são uma das principais fontes emissoras de poluentes, devido à combustão que nos motores ocorrer de forma incompleta, gerando com isso gases, líquidos e partículas sólidas que se acumulam na atmosfera, sendo o dióxido de carbono $\left(\mathrm{CO}_{2}\right)$ o principal gás emitido no processo de combustão interna dos veículos.

Os efeitos de tais emissões se fazem sentir tanto em escala local, quanto em níveis regionais e globais. As mudanças climáticas são os principais impactos causados pela poluição do ar em nível global, e apesar das alterações produzidas ao clima terem seus efeitos imediatos menos percebidos, as conseqüências em longo prazo, poderão ser desastrosas.
O acelerado aumento das concentrações de Gases de Efeito Estufa (GEE), sobretudo de $\mathrm{CO}_{2}$, que é um dos principais GEE, tem como uma de suas maiores conseqüências o aumento da temperatura média do planeta, o chamado aquecimento global, fenômeno que poderá provocar grandes prejuízos ambientais ao planeta.

Devido ao grande consumo energético e à intensidade das emissões poluentes produzidas pela modalidade rodoviária, torna-se relevante o incentivo aos sistemas de transporte com um menor consumo de combustível por passageiro transportado, investindo em modalidades de alta capacidade no transporte de passageiros como a modalidade hidroviária, que tendo o seu potencial de ocupação bem aproveitado apresenta vantagens, como o melhor rendimento energético, além de permitir a redução do número de veículos automotores nas vias, contribuindo com isso para a redução de emissões poluentes.

\section{EMISSÕES DE $\mathrm{CO}_{2}$ E EFICIÊNCIA ENERGÉTICA NO SETOR DE TRANPORTES}

No Brasil, os transportes ocupam a segunda posição em termos de consumo energético, sendo superado apenas pelo setor industrial. O transporte rodoviário participa com 90,2\% de toda a energia consumida por todo o setor (MME, 2002). No sistema de transporte público da Região Metropolitana do Rio de Janeiro o transporte por ônibus vem ocupando desde a década de 50 o espaço destinado ao trem e ao metrô, estes sim modalidades de grande capacidade. Enquanto que em 1950 representava $28 \%$ do total de viagens, atualmente o ônibus responde por quase $80 \%$ deste total. De acordo com dados da Secretaria de Transportes do Município do Rio de Janeiro - Sectran (2003), somente no município do Rio de Janeiro o transporte por ônibus corresponde a mais de $70 \%$ dos deslocamentos, enquanto que as demais modalidades participam com menos de $30 \%$ do total de viagens 
produzidas pelos sistemas de transporte coletivos. A utilização de energia para os transportes no país aumentou bastante da década de 90 ao início do século XXI, sobretudo na modalidade rodoviária, que de 1990 até o ano 2001 obteve um aumento em cerca de $51 \%$ do consumo energético (MME, 2002).

Ao compararmos as diferenças entre eficiências energéticas apresentadas pelas modalidades rodoviária e hidroviária, objeto de estudo deste trabalho, é possível identificar que comparados ao transporte rodoviário, os sistemas hidroviários apresentam-se como um dos menos intensivos no consumo de energia. A potência de uma barca para transportar de 2.000 a 2.100 passageiros corresponde a $1.230 \mathrm{kw}$ (quilowatt), enquanto que para transportar o mesmo número de passageiros por ônibus seriam necessários 30 veículos, correspondendo a $3.357 \mathrm{kw}$ (USACE, 1999).

A Figura 1 a seguir, mostra a comparação entre o consumo energético de uma embarcação e das modalidades ferroviária e rodoviária para o transporte de uma tonelada de carga ou passageiro para cada litro de combustível consumido.

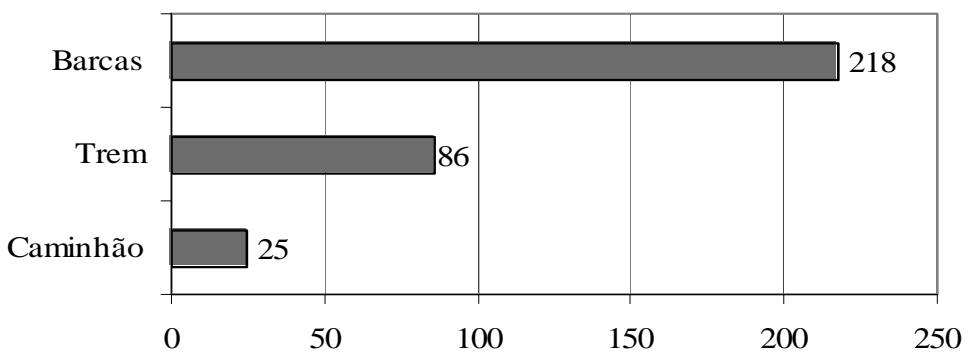

Figura 1: Comparação de Eficiência Energética (em kw) entre as Modalidades de Transporte (USACE, 1999).

Deve-se ressaltar, no entanto, que para as comparações entre a eficiência energética de diferentes modalidades de transportes, devem ser considerados não só o consumo de combustível, mas também outros elementos tais como: os equipamentos utilizados em cada modalidade, as condições técnicas dos locais bem como os procedimentos operacionais empreendidos (Ribeiro, 2002). O sistema hidroviário, por ser de alta capacidade para o transporte de passageiros apresenta um menor consumo de energia per capita, porém, em uma embarcação a eficiência energética só é totalmente aproveitada com a plena utilização de sua capacidade de transporte, ou seja, o consumo de combustível não se justificaria caso a embarcação trafegasse com sua capacidade ociosa de passageiros ou de carga.

ENGEVISTA, v. 6, n. 3, p. 64-74, dezembro 2004

\subsection{EMISSÕES DE $\mathrm{CO}_{2} \quad$ PELOS TRANSPORTES NO MUNICÍPIO DO RIO DE JANEIRO}

Durante a década de 90 ocorreu um crescimento das emissões de $\mathrm{CO}_{2}$ por unidade de energia consumida, o que pode ser justificado pelo decréscimo no consumo de álcool etílico e de álcool etílico hidratado no município do Rio de Janeiro durante esse período. Em um intervalo de oito anos, ou seja, de 1990 a 1998, o consumo de álcool no município obteve uma queda de $561.909 \mathrm{~m}^{3}$. Em contrapartida o álcool etílico anidro que correspondia a $22 \%$ do consumo total de combustíveis, a partir de 1998 passou a representar $24 \%$, não sendo este aumento representativo para a redução das emissões 
de $\mathrm{CO}_{2}$ por unidade de energia consumida no município. No final da década de 90 o transporte coletivo efetuado principalmente por ônibus no Rio de Janeiro obteve uma participação de $36 \%$ das emissões de $\mathrm{CO}_{2}$ do total de emissões produzidas pelos sistemas de transportes analisados, como mostra a Figura 2 a seguir.

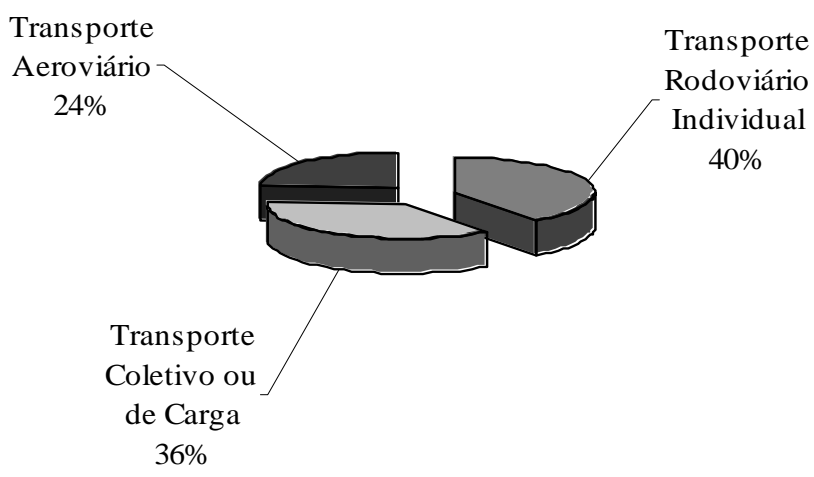

Figura 2: Emissões de $\mathrm{CO}_{2}$ no Setor de Transportes no Município do Rio de Janeiro em 1998 (SMAC/COPPETEC, 2000).

De acordo com o "Inventário de Gases de Efeito Estufa do Município do Rio de Janeiro", elaborado no ano 2000, apesar do aumento no consumo de combustíveis no transporte rodoviário individual, no início da década de 90 o transporte coletivo e de carga lideravam as emissões de $\mathrm{CO}_{2}$ no segmento de transportes rodoviários. Em 1990 o transporte rodoviário individual participava com 16,94\% passando a representar 26,23\% das emissões em 1998, o transporte coletivo e de carga tinham uma participação de 22,21\%, e no final da década de 90 representavam 23,41\% das emissões totais de $\mathrm{CO}_{2}$. Nesse mesmo período, o setor de transportes rodoviário totalizava $49,64 \%$ das emissões comparadas aos demais setores de uso energético.

Os dados do Inventário mostram ainda que as taxas geométricas de crescimento anual para as emissões de $\mathrm{CO}_{2}$ oriundas do consumo de combustíveis fósseis e as emissões totais de $\mathrm{CO}_{2}$ acompanharam o crescimento da população do município em relação ao país. Conclui-se que ocorreu um aumento das emissões no município durante o período de 1996 a 1998, apresentando crescimento médio anual da ordem de $3,6 \%$. Os dados mostram que no caso do município do Rio de Janeiro, os sistemas de transportes representados, ENGEVISTA, v. 6, n. 3, p. 64-74, dezembro 2004 sobretudo pela modalidade rodoviária, são as principais fontes emissoras de $\mathrm{CO}_{2} \mathrm{e}$ que, a exemplo do que ocorre em todo o Brasil, este é o gás de efeito estufa emitido em maior quantidade, considerando as emissões feitas pelo total das atividades econômicas.

\section{ESTUDO DE CASO}

Tendo como peculiaridade o fato de ser operada tanto pelo sistema hidroviário quanto pelo sistema rodoviário no transporte de passageiros, a ligação entre os municípios do Rio de Janeiro e de Niterói apresenta um intenso tráfego de veículos via ponte Rio-Niterói, o que agrava os problemas de congestionamentos dificultando o transporte nesta ligação. A ponte Rio-Niterói foi projetada para absorver um tráfego de 55 mil veículos/dia, apresentando atualmente um fluxo de aproximadamente $130 \mathrm{mil}$ veículos/dia, o que ultrapassa o dobro de sua capacidade. A sua capacidade máxima de escoamento é de aproximadamente 6.000 veículos/hora em cada sentido, havendo, em horários de pico, um excedente de dois mil veículos por hora na pista em direção ao Rio de Janeiro, o que causa graves problemas de congestionamentos nas alças de acesso à 
ponte e nas cidades de Niterói e de São Gonçalo.

Apesar da paisagem da Baía de Guanabara proporcionar viagens mais prazerosas e também do trajeto ser feito em um menor tempo (20 minutos) que nas viagens via ponte (30 minutos), devido à não ocorrência de congestionamentos, durante os últimos anos, observa-se um crescente aumento da preferência dos passageiros pelo sistema rodoviário em detrimento ao sistema hidroviário na travessia Rio-Niterói (BNDES, 1999).

Todavia, é importante destacar, que os intervalos de saídas entre as embarcações com o aumento do tempo médio das viagens por barcas, bem como as eventuais trocas de modalidades que alguns usuários necessitam fazer na chegada aos municípios do Rio de Janeiro e de Niterói, devem ser considerados para explicar a migração de usuários para o sistema rodoviário.

\section{1. ÁREA DE ESTUDO}

A ligação de transporte de passageiros entre os municípios do Rio de Janeiro e de Niterói é uma das mais importantes dentro da Região Metropolitana do Rio de Janeiro, realizada simultaneamente pelos modos rodoviários e hidroviários, sendo este último composto por: barcas aerobarcos e catamarãs. Os principais municípios geradores de viagens são Niterói e São Gonçalo, e a modalidade hidroviária assume nesta ligação características de transporte de massa, existindo também a possibilidade de escolha por parte dos passageiros pelo acesso rodoviário feito através da ponte Rio-Niterói. Tal fato confere a esta travessia características particulares dentro do segmento de transportes de passageiros no país (Cid et al, 1999). A partir da inauguração da ponte Rio-Niterói (em 1974) ocorreu a entrada em operação de linhas de transporte rodoviário competindo diretamente com o sistema hidroviário.
Atualmente, cerca de 75 mil passageiros são transportados por barcas, sendo, porém, o transporte coletivo por ônibus e por automóveis os mais utilizados, deslocando cerca de 121.000 passageiros/dia, tendo um fluxo de veículos pendular, ou seja, todos os veículos vão e voltam de Niterói para o Rio de Janeiro e vice-versa, sendo feita por isso a cobrança de pedágio somente em um sentido (Ponte S.A., 2004).

\subsection{VARIÁVEIS UTILIZADAS}

As variáveis utilizadas para a quantificação de emissões de $\mathrm{CO}_{2}$ produzidas pelo sistema de barcas serão: o consumo de combustível, o número de viagens produzidas, distância percorrida e total de passageiros transportados pelas barcas na ligação Praça XV-Praça Araribóia por um período correspondente a dez anos.

As informações utilizadas neste estudo de caso foram retiradas da pesquisa feita em Pinto (2004), sendo disponibilizadas pelos seguintes órgãos: Secretaria de Transportes do Rio de Janeiro Sectran-RJ, Departamento de Transportes Rodoviário do Rio de Janeiro Detro-RJ, Agência Reguladora dos Serviços Públicos Concedidos Asep-RJ e Concessionária Barcas S.A.

\subsection{OBJETO DE ESTUDO}

A linha de barcas que faz a ligação Praça XV-Niterói é a maior do Brasil, em número de passageiros, frota e capacidade das embarcações, porém, é possível constatar que nos últimos anos o número total de passageiros transportados vem sofrendo um decréscimo. A média diária de passageiros em dias úteis sofreu significativas alterações, passando de 71.500 passageiros transportados no final de 1998 para 52.500 no final de 2003. Segundo a operadora do sistema, a redução na demanda a partir do ano de 2002 deve-se à necessidade de revitalização da frota operante iniciada a partir do ano 2002, sendo a manutenção da frota uma das cláusulas do contrato de 
concessão feito a partir de 1998, quando a operação do sistema hidroviário de passageiros do Rio de Janeiro foi transferido à iniciativa privada, passando a ser administrado pela Concessionária Barcas S.A. O tempo de docagem necessário ao processo de reparo das embarcações tem duração de aproximadamente quatro a sete meses, o que retira de operação as embarcações em manutenção, reduzindo com isso o número de viagens produzidas durante o período.

Com relação aos aspectos operacionais do sistema hidroviário Praça XV-Niterói, a frota é compota por 14 embarcações, sendo o percurso percorrido a cada viagem de 2,7 milhas, o que corresponde a $5,0 \mathrm{Km}$. A capacidade total de transporte das embarcações é de 23.370 passageiros, sendo o óleo diesel marítimo o combustível utilizado, com um consumo médio de 135,11 litros por viagem (Barcas S.A, 2003).

\subsection{METODOLOGIA}

De forma que se possa ter uma base comum de comparação entre as emissões de gases de efeitos estufa dos diferentes países, foi elaborada pelo Intergovernmental Panel on Climate Change - IPCC uma metodologia para a quantificação de emissões de $\mathrm{CO}_{2}$ a ser seguida e apresentada nas "Diretrizes para Inventários Nacionais de Gases de Efeito Estufa” de 1996 (MCT, 2002). A metodologia do IPCC foi oficialmente adotada pela Convenção do Clima na elaboração das Comunicações Nacionais dos diversos países signatários da Convenção, dentre eles o Brasil.

De acordo com os dados disponíveis esta metodologia pode ser aplicada a partir de duas abordagens distintas: a abordagem top-down ou a abordagem bottom-up. A aplicação de uma ou de outra depende basicamente do nível de agregação dos dados. A metodologia top-down permite o cálculo das emissões de $\mathrm{CO}_{2}$ usando apenas os dados relativos à oferta sem o detalhamento a respeito do consumo.

Para este estudo de caso a escolha da metodologia top-down deu-se em função dos dados obtidos. Desta forma, as variáveis diretamente utilizadas correspondem ao consumo e ao tipo de combustível fóssil utilizado no sistema de transporte hidroviário em estudo.

Resumidamente, em uma primeira etapa da aplicação da metodologia top-down é preciso converter o consumo aparente do combustível para uma unidade comum de energia, ou seja, o tera-joules (TJ), que corresponde a um tep brasileiro $\left(45,2 \times 10^{-3}\right.$ TJ). Em seguida, procede-se à transformação do consumo aparente do combustível em conteúdo de carbono pela multiplicação do fator de emissão de carbono relativo ao tipo de combustível utilizado. Os fatores de emissão, de conversão e correção de unidades de massa e volume foram obtidos no Balanço Energético Nacional do Ministério das Minas e Energia (2002). De forma simplificada, o cálculo do volume de $\mathrm{CO}_{2}$ em derivados de petróleo é feito a partir da aplicação da Equação (1), abaixo:

$$
\text { CC }=\text { CA } x \text { FConv } \times 45,2 \times 10^{-3} \times
$$

$$
\text { FCorr }
$$

Sendo:

$\mathrm{CC}=$ Consumo de Energia (TJ)

$\mathrm{CA}=$ Consumo Aparente do Combustível (unidade física: $\mathrm{m}^{3}, \mathrm{~L}$, $\mathrm{t}$, etc.)

FConv $=$ Fator de Conversão (tep/unidade física)

FCorr = Fator de Correção de Poder Calorífico (adimensional)

A última etapa da metodologia top-down consiste no cálculo das emissões reais de $\mathrm{CO}_{2}\left(\mathrm{ERCO}_{2}\right)$, que é feito a partir das emissões reais de carbono. Desta forma, pode-se então calcular as emissões reais de $\mathrm{CO}_{2}\left(\mathrm{ERCO}_{2}\right)$ oriundas da utilização de energia.

Para esse cálculo, leva-se em conta seu conteúdo de carbono (em 44 ton de $\mathrm{CO}_{2}$ há 12 ton de carbono, ou seja, 1 ton $\mathrm{CO}_{2}=$ 
0,2727 tC). A partir da Equação (2) mostrada a seguir, é feito o cálculo da $\mathrm{ERCO}_{2}$.

Sendo:

$$
\mathrm{ERCO}_{2}=\mathrm{ERC} \times(44 / 12)
$$

$\mathrm{ERCO}_{2}=$ Emissões Reais de $\mathrm{CO}_{2}\left(\mathrm{GgCO}_{2}\right)$ $\mathrm{ERC}=$ Emissões Reais de Carbono (GgC)

Para facilitar comparações entre os resultados, a unidade recomendada pelo IPCC para os inventários é o $\mathrm{GgCO}_{2}$ (Giga grama de $\mathrm{CO}_{2}$ ), sendo que $1 \mathrm{GgCO}_{2}$ equivale a 1.000 toneladas de $\mathrm{CO}_{2}$.

\subsection{CENÁRIOS ALTERNATIVOS}

A partir do desenvolvimento dos cenários futuros para o sistema de transporte por barcas, busca-se investigar o quanto em emissões de $\mathrm{CO}_{2}$ poderiam ser evitadas caso ocorresse uma maior utilização da modalidade hidroviária nesta ligação. Serão apresentados dois cenários alternativos em que foram feitas projeções para as emissões de $\mathrm{CO}_{2}$ por um período de dez anos, de 2004 a 2013. Os cenários mostram duas situações distintas: 0 primeiro deles estabelecerá a hipótese de que nenhuma alteração venha a ocorrer no sistema hidroviário para os próximos dez anos (Cenário Alternativo A). No segundo, serão considerados os potenciais de redução para as emissões de $\mathrm{CO}_{2}$ per capita, caso haja um aumento na demanda de passageiros no sistema hidroviário (Cenário Alternativo B).

Para o desenvolvimento dos cenários alternativos estabeleceu-se inicialmente uma análise de referência que mostra as oscilações verificadas para a demanda de passageiros, consumo de combustível e emissões de $\mathrm{CO}_{2}$ observados por um período de dez anos, de 1994 a 2003.

A quantificação das emissões de $\mathrm{CO}_{2}$ foi feita a partir da aplicação da metodologia top-down anteriormente descrita, utilizando-se dados relativos ao consumo anual de diesel marítimo.

A seguir, são mostradas na Tabela 1 as variações anuais para o consumo de combustível e emissões de $\mathrm{CO}_{2} /$ passageiro no sistema hidroviário relativos ao período de 1994 a 2003.

É possível constatar que durante o período analisado ocorreu uma queda da eficiência energética do sistema, e como conseqüência o aumento das emissões per capita de $\mathrm{CO}_{2}$. As emissões médias apresentadas em todo o período foram de 0,0009 $\mathrm{Gg} \mathrm{CO}_{2}$ por passageiro/ano.

Tabela 1: Consumo de Combustível e Emissões de $\mathrm{CO}_{2}$ de 1994 a 2003

\begin{tabular}{cccccc}
\hline Ano & $\begin{array}{c}\text { Cons. de } \\
\text { Combustível } \\
\text { (l/ano) }\end{array}$ & Emissão/Pass. & Ano & $\begin{array}{c}\text { Cons. de } \\
\text { Combustível } \\
\text { (l/ano) }\end{array}$ & Emissão/Pass. \\
\hline 1994 & 6.446 .098 & 0,0008 & 1999 & 6.474 .471 & 0,0009 \\
1995 & 6.436 .640 & 0,0008 & 2000 & 7.029 .908 & 0,0009 \\
1996 & 6.485 .550 & 0,0009 & 2001 & 7.016 .938 & 0,0009 \\
1997 & 6.465 .014 & 0,0010 & 2002 & 5.951 .190 & 0,0010 \\
1998 & 6.446 .098 & 0,0009 & 2003 & 5.574 .909 & 0,0010 \\
\hline
\end{tabular}

A partir desta análise preliminar serão desenvolvidos nos itens a seguir os cenários alternativos A e B.

\subsubsection{CENÁRIO ALTERNATIVO A}

O cenário alternativo A apresenta as tendências observadas para as emissões de
$\mathrm{CO}_{2}$ pelo transporte por barcas assumindo a hipótese de que nenhuma alteração seja

produzida ao sistema pelos próximos dez anos. Neste caso, a demanda de passageiros manterá a mesma tendência apresentada nos dez anos anteriores, e os resultados mostram que as emissões per capita de $\mathrm{CO}_{2}$ apresentarão um aumento para os 
próximos dez anos caso não ocorra nenhuma alteração ao sistema e ao número de passageiros transportados. As previsões para este cenário indicam que haverá uma redução da eficiência energética do sistema e um aumento em cerca de 0,0001 Gg por passageiro transportado, passando a ser de $0,0011 \mathrm{GgCO}_{2}$ por passageiro/ano. A Tabela 2 mostra as estimativas para as emissões de $\mathrm{CO}_{2}$ projetadas de 2004 a 2013.

Tabela 2: Emissões de $\mathrm{CO}_{2}\left(\right.$ em $\left.\mathrm{GgCO}_{2}\right)$ - Cenário A

\begin{tabular}{cccc}
\hline Ano & Emissão/Passageiro & Ano & Emissão/Passageiro \\
\hline 2004 & 0,0010 & 2009 & 0,0011 \\
2005 & 0,0010 & 2010 & 0,0012 \\
2006 & 0,0011 & 2011 & 0,0012 \\
2007 & 0,0011 & 2012 & 0,0012 \\
2008 & 0,0011 & 2013 & 0,0013 \\
\hline
\end{tabular}

\subsubsection{CENÁRIO ALTERNATIVO B}

Atualmente, estão sendo feitos investimentos em um projeto de expansão do sistema hidroviário do Rio de Janeiro tendo a participação do Banco Nacional de Desenvolvimento Social - BNDES e do Fundo de Marinha Mercante. Tais investimentos visam à melhoria do sistema e a intensificação do transporte hidroviário de passageiros.

De acordo com previsões feitas pelos investidores, com a introdução de melhorias, dentre elas: reforma dos terminais e da frota operante e expansão das linhas pretende-se atrair os usuários dos sistemas rodoviários, aumentando a demanda de passageiros para os próximos anos. A taxa de ocupação do sistema de barcas fora dos horários de pico é de $50 \%$, havendo desta forma, um potencial para a expansão do número de passageiros transportados por embarcação nos horários intermediários.

Desta forma, o cenário B foi desenvolvido a partir da hipótese de que as expectativas da empresa operadora se confirmem, considerando que ocorra um aumento para a demanda de passageiros do sistema hidroviário nos próximos anos, o que de acordo com a própria operadora estima-se em torno de $80 \%$ para o próximo período. A seguir, a Tabela 3 apresenta os cálculos para as emissões de $\mathrm{CO}_{2}$ estimadas para o cenário alternativo B.

Tabela 3: Emissões de $\mathrm{CO}_{2}\left(e m \mathrm{GgCO}_{2}\right)$ - Cenário B

\begin{tabular}{cccc}
\hline Ano & Emissão/Passageiro & Ano & Emissão/Passageiro \\
\hline 2004 & 0,0006 & 2009 & 0,0007 \\
2005 & 0,0006 & 2010 & 0,0007 \\
2006 & 0,0006 & 2011 & 0,0007 \\
2007 & 0,0007 & 2012 & 0,0008 \\
2008 & 0,0007 & 2013 & 0,0008 \\
\hline
\end{tabular}

3.5.3. COMPARAÇÃO ENTRE OS CENÁRIOS A E B E EMISSÕES EVITADAS

ENGEVISTA, v. 6, n. 3, p. 64-74, dezembro 2004
A seguir são mostradas as emissões de $\mathrm{CO}_{2}$ reduzidas a partir da comparação entre os resultados obtidos nos dois cenários. É possível constatar que caso haja um 
aumento da demanda de passageiros, hipótese estabelecida no cenário $\mathrm{B}$, haverá uma redução de emissões de $\mathrm{CO}_{2}$ em média para $0,0004 \mathrm{GgCO}_{2} /$ ano para cada passageiro transportado pelo sistema de barcas, ou seja, cerca de 0,4 tonelada de
$\mathrm{CO}_{2}$ por passageiro serão reduzidas a cada ano. A Tabela 4 a seguir apresenta a redução de emissões de $\mathrm{CO}_{2}$ projetadas a partir da comparação entre os cenários alternativos A e B.

Tabela 4: Emissões de $\mathrm{CO}_{2}\left(\mathrm{em} \mathrm{GgCO}_{2}\right)$ Evitadas - Comparação entre os Cenários

\begin{tabular}{lccc}
\hline Ano & Emissões Evitadas & Ano & Emissões Evitadas \\
\hline 2004 & 0,0004 & 2009 & 0,0004 \\
2005 & 0,0004 & 2010 & 0,0005 \\
2006 & 0,0005 & 2011 & 0,0005 \\
2007 & 0,0004 & 2012 & 0,0004 \\
2008 & 0,0004 & 2013 & 0,0005 \\
\hline
\end{tabular}

É importante destacar que ocorrendo o aumento na demanda de passageiros em no sistema de transporte da ligação RioNiterói com a expansão do transporte por barcas, além de menores emissões per capita do próprio sistema hidroviário ocorrerão também reduções a partir da menor utilização do transporte por ônibus, o que se dará através da transferência de passageiros usuários do sistema rodoviário ao hidroviário.

\section{CONCLUSÕES E CONSIDERAÇÕES}

Dentro do contexto de maior eficiência energética dos sistemas de transporte buscou-se, a partir de um estudo de caso, estabelecer neste artigo uma relação entre o maior aproveitamento energético pelos sistemas de transporte público, através da expansão da modalidade hidroviária, e a redução das emissões de $\mathrm{CO}_{2}$, um dos principais gases de efeito estufa.

Os resultados obtidos neste estudo de caso mostram que a expansão do sistema hidroviário de passageiros na ligação RioNiterói produziria ganhos ambientais no sentido de mitigar o problema do efeito estufa. Além disso, a maior utilização dos sistemas de alta capacidade no transporte de passageiros, proporcionam um melhor planejamento dos sistemas de transportes públicos, oferecendo maiores alternativas para os usuários do transporte coletivo. Todavia, os resultados apresentados pelos cenários alternativos mostram que caso não haja interferências para um efetivo aumento na demanda de passageiros do sistema hidroviário Rio-Niterói haverá conseqüentemente uma redução da eficiência energética do sistema e um aumento dos níveis per capita de emissões de $\mathrm{CO}_{2}$. Ao contrário, com o aumento da demanda de passageiros, o que se prevê com a introdução de reformas ao sistema de barcas, a eficiência energética será satisfatória e as emissões de $\mathrm{CO}_{2}$ apresentariam uma redução expressiva para os próximos dez anos.

Destaca-se, que apesar da modalidade hidroviária apresentar-se energeticamente mais eficiente que os sistemas rodoviários, a efetiva ocupação das embarcações tem importância crucial para o aumento da eficiência energética e por conseqüência para a redução das emissões.

Na prática, o processo de substituição de modalidades que produzem maiores emissões poluentes como é o caso da rodoviária por outras menos poluentes, apresenta uma série de fatores limitantes, como: facilidades oferecidas para o embarque e desembarque de passageiros, o 
fator tempo, a infra-estrutura do sistema de transportes, as tecnologias empregadas, além dos aspectos econômicos relativos à implantação e manutenção do próprio sistema.

Todavia, existem grandes perspectivas para o transporte hidroviário de passageiros, tanto a nível mundial quanto nacional. $\mathrm{O}$ Brasil, embora em ritmo mais lento, vem seguindo a tendência internacional e tenta recuperar o papel do transporte hidroviário em cidades que dispõem dessa modalidade no transporte de passageiros. Atualmente, com a concessão de vários sistemas hidroviários à iniciativa privada ocorre um maior envolvimento dos órgãos governamentais gestores com a questão dos tempos de viagem, além de maiores investimentos em projetos de reestruturação dos sistemas e na melhoria das embarcações. Destaca-se o uso de novas tecnologias de motorização e propulsão proporcionando aumento da velocidade das embarcações e novos layouts para os terminais de embarque e desembarque, diminuindo com isso, o tempo gasto nestes procedimentos.

Em relação ao sistema hidroviário do Rio de Janeiro foram feitos investimentos em torno de US\$ 75 milhões negociados junto ao BNDES e ao Fundo de Marinha Mercante para que sejam feitas reestruturações que entre outras, incluem a modernização da frota, a ampliação das linhas e a construção de novos terminais, como o que liga o bairro de Charitas à Praça XV, além da renovação da frota com introdução de novas embarcações do tipo catamarãs, com design italiano e casco em alumínio, o que possibilita o aumento da velocidade de operação e redução nos tempos de viagem.

Em relação às emissões atmosféricas, existem interesses por parte dos países desenvolvidos, que são os maiores emissores de GEE, em investirem no desenvolvimento de projetos de reduções de emissões em países em desenvolvimento. A participação nestes projetos permite ao país financiador a obtenção de créditos em emissões mensuráveis em toneladas de carbono. As estratégias para a mitigação de emissões de $\mathrm{CO}_{2}$, assim como de outros GEE oriundos do setor de transportes, devem ser analisadas estabelecendo interações entre as reduções locais, buscando com isso mitigar o problema das emissões em níveis globais. Como exemplo de ações locais temos a Campanha Cidades na Proteção do Clima (Cities for Climate Protection CCP). Alguns municípios brasileiros como o Rio de Janeiro integram esta campanha, assumindo o compromisso de promover metas de ações locais para a redução dos níveis de GEE em todos os setores econômicos. Torna-se, portanto, de extrema importância conhecer a evolução das emissões de $\mathrm{CO}_{2}$ nas grandes cidades brasileiras, tendo no setor de transportes um alvo de grande interesse para o desenvolvimento de estratégias de mitigação de GEE.

\section{BIBLIOGRAFIA}

BARCAS S.A. (2003). Comunicação pessoal com a empresa.

BNDES (1999). "Transporte Hidroviário Urbano de Passageiros”, Cadernos de Infra-Estrutura $n^{\circ} 13$, Set/99.

CID, L. C., SARAÇA, C. E. dos SANTOS e CARREGOSA, A. C. A (1999). "População" in: Niterói: Perfil de Uma Cidade. pp. 95-154, Secretaria Municipal de Ciência e Tecnologia, Niterói.

MCT (2002). Primeiro Inventário Brasileiro de Emissões Antrópicas de Gases de Efeito Estufa - Relatórios de Referência "Emissões de Dióxido de Carbono por Queima de Combustíveis: Abordagem top- down, COPPE/UFRJ, Rio de Janeiro.

MME (2002). Balanço Energético Nacional - BEN 2001, Ministério das Minas e Energia, Brasília - DF.

RIBEIRO, S., K., (org.) (2002). “Barreiras na Implantação de Alternativas Energéticas para o Transporte Rodoviário no Brasil”, Centro de Estudos Integrados 
Sobre Meio Ambiente e Mudanças

Climáticas - Centro Clima -

COPPE/UFRJ, Rio de Janeiro.

PINTO, F., C., V., (2004). Potencial de

Redução de Dióxido de Carbono Através

do Emprego de Modalidades de Transporte

Energeticamente Mais Eficientes: O Caso

da Travessia Rio-Niterói. Tese de M. Sc.

PET/COPPE/UFRJ, Rio de Janeiro.

PONTE S.A. (2004). Comunicação pessoal com a empresa.

SCHIPPER, L., \& MARIE-LILLIU, C., (1999). Transportation and $\mathrm{CO}_{2}$ Emissions: Flexing the Link - a path for the World Bank, International Energy Agency, Paris.

SECTRAN (2003). Disponível em: http://www.sectran.rj.gov.br.

SMAC/COPPETEC (2000). Inventário de Gases do Efeito Estufa do Município do Rio de Janeiro, COPPE/UFRJ, Rio de Janeiro.

USACE - U.S. Army Corps of Engineers (1999). Transportation Mode Comparison. 